\title{
GROVE
}

\section{The Effect of Salt Solutions on Germination}

General Science

A. B.

1913
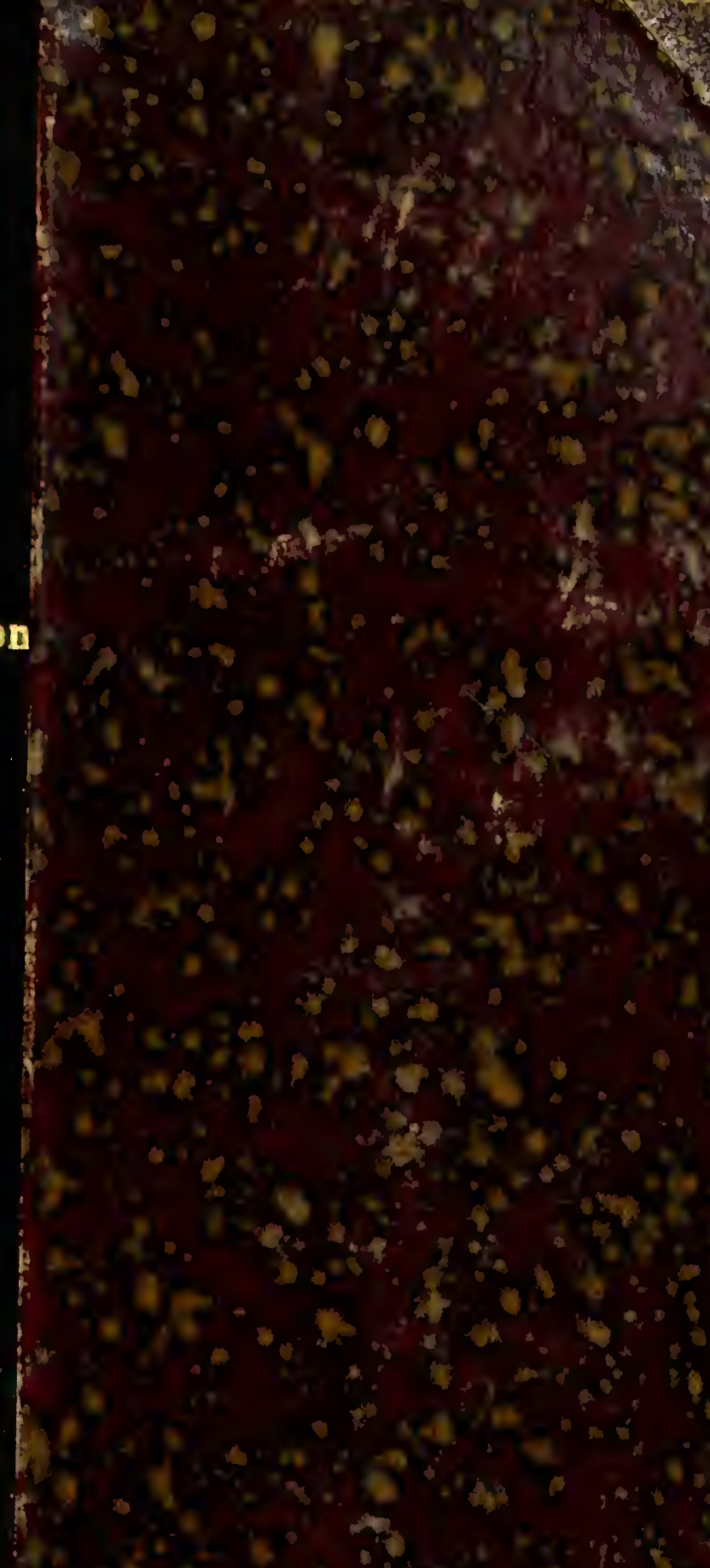

intat? 
THE UNIVERSITY

\section{OF ILLINOIS}

LIBRARY

1913

G89 


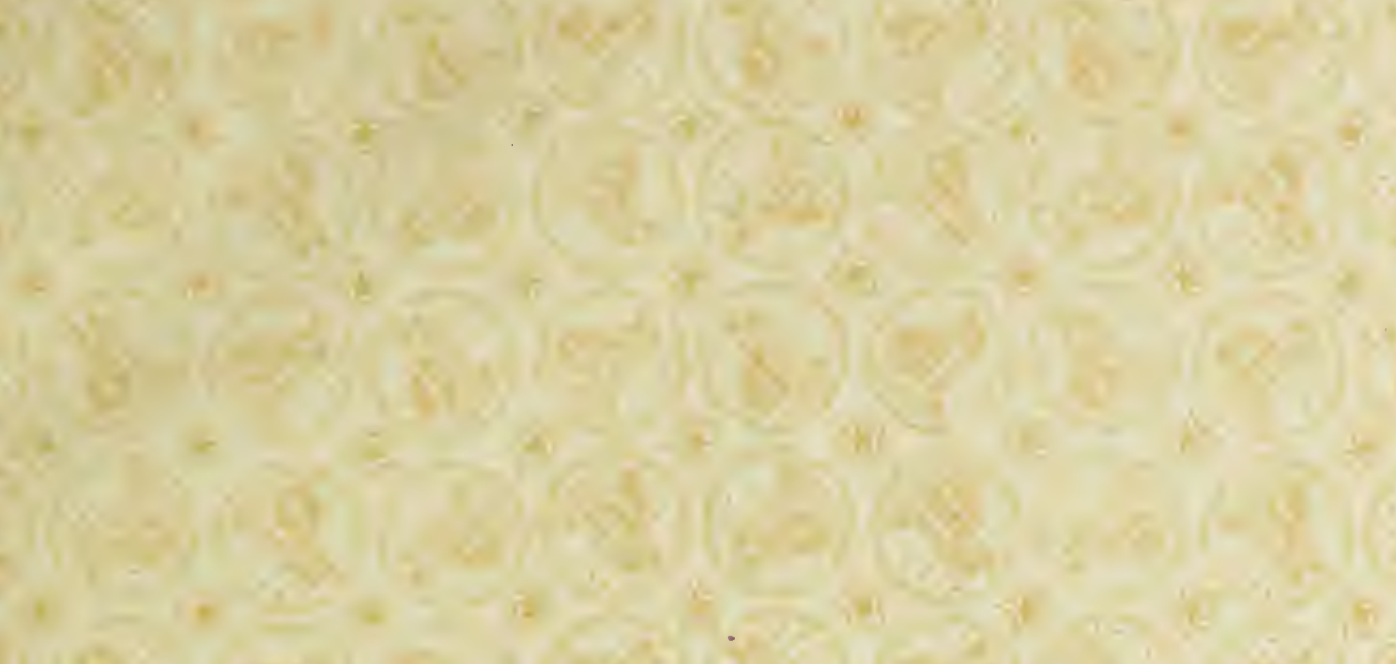

$(2+5)+2=0$

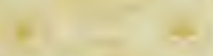

19

4

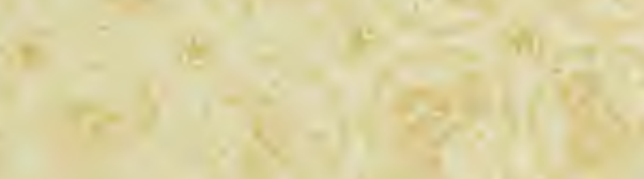

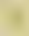

4

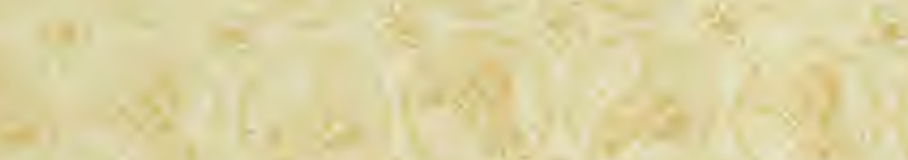

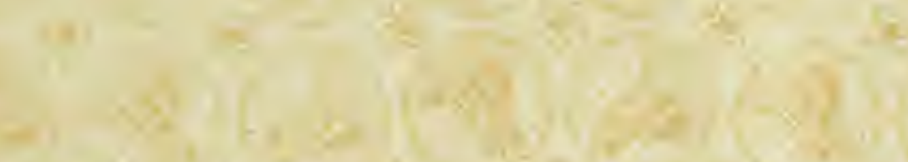

$+\frac{1}{2}$,

$y=$

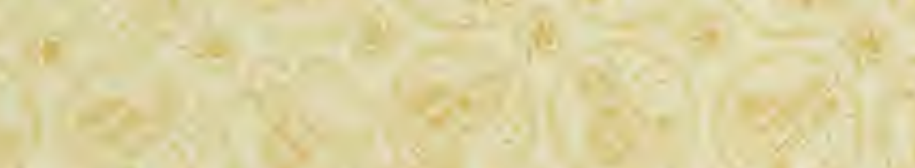

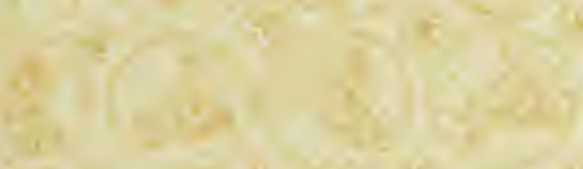

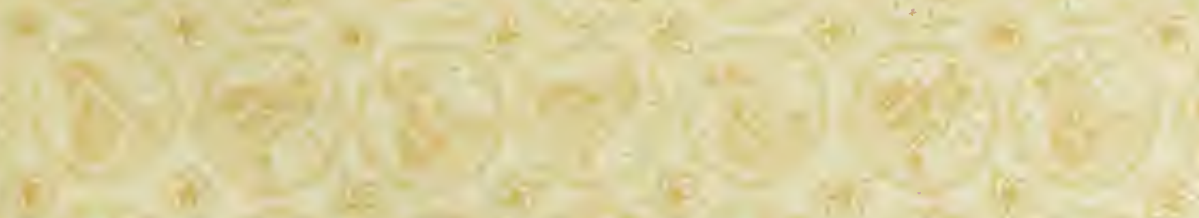

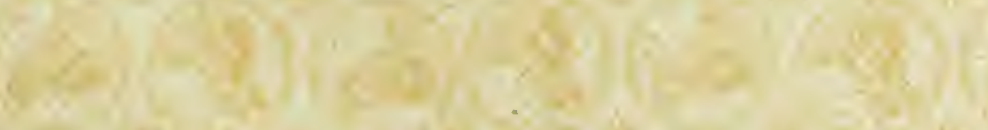

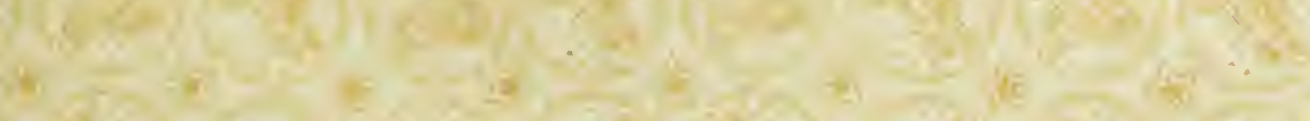

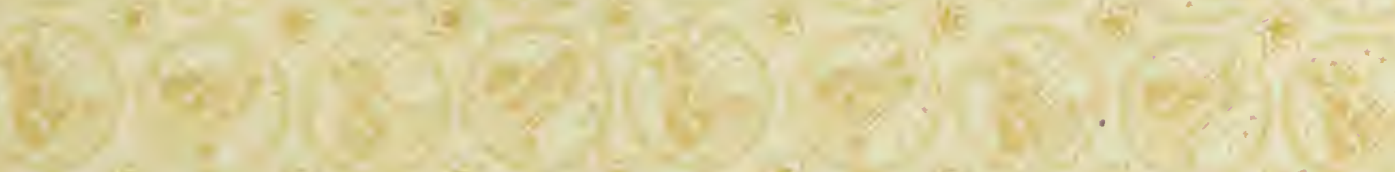

6.

$-x^{2}$

Q 
Digitized by the Internet Archive in 2014 


\author{
THIE IEFISCY \\ or \\ SAIT SOLU'TIONS ON GERMINATION
}

BY

PEARI, FOREST GROVE

\title{
THES IS
}

FOR THE

\section{DEGREE OF BACHELOR OF ARTS \\ IN \\ SCIENCE}

COLLEGE OF SCIENCE

UNIVERSITY OF ILLINOIS 

UNIVERSITY OF ILLINOIS

May 29,

1913

THIS IS TO CERTIFY THAT THE THESIS PREPARED UNDER MY SUPERVISION BY Pearl Forest Grove

ENTITLED The Effect of Salt Sclutions on Germination.

IS APPROVED BY ME AS FULFILLING THIS PART OF THE REQUIREMENTS FOR THE

DEGREE OF Bachelor of Arts

In General science

Chas. F. Atotes

Instructor in Charge

APPROVED: Chase F. Nottes

Acting HEAD OF DEPARTMENT OF ........ Botany 
$\infty$ 
COIT TEN ITS.

I. Introduction--

Page

1. Investigations of Vandevelde--

2. Wethods--

3. Tests for percentage of Germination--

II. Discussion of Experiments and results--

1. Canada field peas--

(a) First series--

(b) Second series--

2. Mite lilarrow-fat peas--

3. Telephone peas--

II. Conclusion--

PIÁPE

$I$.

PLATE

II.

PIATE III.

PIATE IV.

ELATE $V$.

IIATE VI.

PIATE VII.

PIATE VIII.
Fage 16.

$\begin{array}{ll} & 17 . \\ & 18 . \\ & 19 . \\ & \\ & 20 . \\ & 21 . \\ & 22 . \\ & 23 .\end{array}$



THE EFELCT OF SALT SOLUTICIS ON GERMITATIOH.

I. Introduction.

The relation between the growth of plants and concentration of solutions has been studied a great deal. Among those who heve contributed to this subject are:- Jerius ('86), Jentys ('88), Stange ('92), Vandevelde (197) and others. The results obtained by these investigators are far from being concordant.

1.- Investigations of Vandevelde.

The experiments of Vandevelde are especially interesting and have been considerably referred to in the general literature relative to the effect of concentration of solution on germination and growth.

His results as obtained by treating the seeds of the common pea, Iisum sativum, are so difficrlt to correlate that it was desmed profitable to repeat his experiments with the vien of correcting or explaining the irregularities. He soaked the seeds for 24 hours in solutions of common salt varying from 1 per cent to 35 per cent and then placed them in pans for germination.

Fis results may be noted as follows:-

G, per cent of seeds that germinated, I, the mean interval elapsing in deys before one half of the seeds germinated and $c_{i}=$ per cent of solution. 



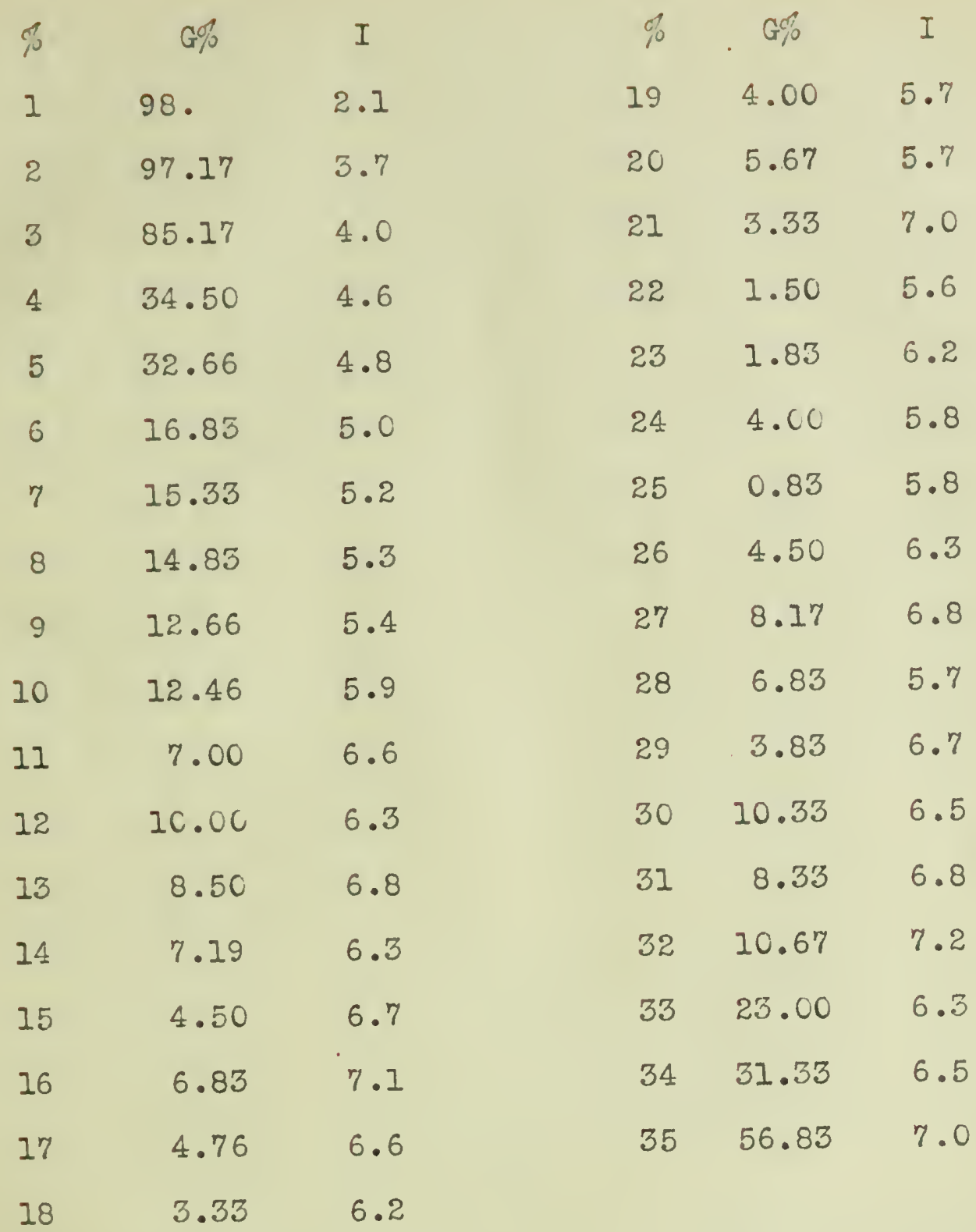

The results as presented in this table, are discussed by Davenport as follows:- As the corcentration increases from one per cent to fifteen percent, the percentage of germination diminishos rom 98 to 4.5 and the mean germination interval increases from 2.1 days to nearly 7 near which point it romains at all higher concentrations. From 15 per cent to 29 per cent the percentage of germinations fluctuate so irregularily between 6.8 and 0.83 that within these limits it may be considered constant. 

As tie corcontration increases from 29, instead of the seeds all being hilled or falling to germinate we have tilo interesting result that the percentnge of germinating individuals rises rapidy from 4 to 56. Vandevelde hazaras the folloming explanation of this result: "Dilute solutions are essily aosorbed; the more concentrated the solution, the smalier the power of diffusion. In a saturated solution the seeds do not svell and the action of the surrounding medium is less injurious."

The apparatus usea by Vandevelde for germinating the seeds coxisted of porus clay plates wich were covered with flannel strips dinned in rater and laid in zinc containers or boxes. The whole spparatus was placed in wooden chests, which were kept in a cellar at a fairly uniform temperature.

\section{2.- Methods.}

In repeating the experiments of Vandevelàe it was found best to modify his methods as follows:- All seeds vere soared bufore germination either in distiled water or in a salt solution of definite concentration.

Those soalied in aistilled water served as checks; the others. in salt solutions varying from one per cent to thirty-five per cent. The apparatus first used consisted of a covered pan furnished with moist filter paper on which were placed the seeds for germination. This method secmed to vork very veli for seeds soared in wear solutions, but for solutions of higher concentration, in wich delayed, the seeds rould mold before germinating. Hence a method was sought that rould prevent this. Zurich germinating dishes rere next used, but with no better siccess. liext, 

a pan with a piece of towling stretched across it was set in a largor pan containing weter. The free onds of the toviling dipnou into the water and maintained the supply of moisture. The seeds were placed on the cloth and another pan inverted over the one containing the water.

Ine seeds wich remained had after being in the germinating pans tal five or six days were removea, soaked in tap water for 24 hours. It ras found that the per cent of germination of these seeds is not in the least affected by the treatment with salt solution of high concentration.

The experiments nere conducted for a time in the laboratory at ordinary room temperature. The temperature fluctuated so much that it was found necessary to conduct the experiments in a room of relatively constant temperature.

nother method of germination was also used. This method is equally as good as the last one doscribed and is as follows. Dlaster-of-paris plates about six inches square and one inch thick were covered rith dampened clotins and placed in a covered tub. The seeds were placed on these cloths. By this method I vas enabled to use a much larger number of seeds ana consequentiy run a considerable series under identical corditions.

The plates coula bo easily sterilized by heat and were more corvenient than the towling wich had to be stretched over the pans Untreated seeds, by a series of tests, demonstrated the methods of germination to be very satisfactory.

3.- Tests for percentage of germination.

The following varieties of peas vere used in the experiments. 

Canada field peas were first used. The seeds were soaked in distilled wter for 24 hours and then placed in germinating pans with the following results:

$\begin{array}{cccc}\text { Tests } & \text { No. Seeds used. } & \text { G } & I \\ 1 & 200 & 97.5 & 1.07 \\ 2 & 200 & 97.0 & 2.2 \\ 2 & 100 & \frac{97.0}{97.1} & \frac{2.6}{1.83} \text { Gen. Aver }\end{array}$

inite harrow-fat peas were soaked in distilled water for 24 hours and then placed in germinating pans with the following results:

$\begin{array}{cccc}\text { Test } & \text { No. Eeas } & \text { G\% } & I \\ 1 & 300 & 96 & 1: 602\end{array}$

relephone Peas were soaked in distilled water for 24 hours and then placed in germinating pans with the following results:

$\begin{array}{cccc}\text { Test } & \text { IIo. Seeds } & \text { G\% } & I \\ 1 & 200 & 96 & 1.32\end{array}$

II.- Discussion of Experiments and Results.

I.- Canada Field Deas.

(a)- First series.- The following are the results of a series of experiments to test the germination of the Canada Field pea after having been soaked in solutions of common salt, 1 percent to 35 percent for 24 hours. 

TABIE III.

\begin{tabular}{|c|c|c|c|c|c|c|c|}
\hline$\%$ & Ge & I & S. G. & $\varsigma_{0}$ & $G r^{1}$ & I & S. G. \\
\hline 1 & 97.78 & 2.32 & 1.0065 & 19 & 5.15 & 2.6 & 1.112 \\
\hline 2 & 90.48 & 2.44 & 1.012 & 20 & 5.15 & 3.8 & 1.119 \\
\hline 3 & 59.31 & 3.4 & 1.019 & 21 & 8.24 & 2.25 & 1.125 \\
\hline 4 & 32.86 & 3.71 & 1.025 & 22 & 6.18 & 3.5 & 1.132 \\
\hline 5 & 22.46 & 3.77 & 1.032 & 23 & 7.21 & 1.28 & 1.137 \\
\hline 6 & 15.5 & 1.67 & 1.038 & 24 & 8.24 & 2.77 & 1.144 \\
\hline 7 & 13.49 & 2.00 & 1.047 & 25 & 10.03 & 2.00 & 1.151 \\
\hline 8 & 12.36 & 2.33 & 1.051 & 26 & 9.27 & 2.77 & 1.157 \\
\hline 2 & 11.33 & 2.18 & 1.0575 & 27 & 10.3 & 1.8 & 1.164 \\
\hline 10 & 11.33 & 2.18 & 1.065 & 28 & 12.36 & 2.25 & 1.170 \\
\hline 11 & 5.15 & 2.8 & 1.070 & 29 & 12.36 & 2.25 & 1.170 \\
\hline 12 & 6.18 & 2.16 & 1.067 & 30 & 10.3 & 2.31 & 1.189 \\
\hline 13 & 6.18 & 2.16 & 1.075 & 31 & 13.4 & 2.23 & 1.196 \\
\hline 14 & 4.12 & 4.5 & 1.080 & 32 & 24.9 & 2.33 & 1.202 \\
\hline 15 & 11.33 & 3.72 & 1.089 & 33 & 20.6 & 1.95 & 1.209 \\
\hline 16 & 3.09 & 2.66 & 1.093 & 34 & 27.8 & 2.07 & 1.215 \\
\hline 17 & 5.15 & 2.00 & 1.098 & 35 & 51.5 & 1.6 & 1.221 \\
\hline 18 & 6.18 & 1.66 & 1.106 & & & & \\
\hline
\end{tabular}

The restits recorded in table III agree very closely with those of Vandevelde. This is clearly brought out in the graphs represented in Plate $I$.

Whe increased time before germination of seeds sosked in salt solutions from 1 to $6 \%$ is due to the lower temperature at wich these seeds were zept for germination. Time did not allow a repetition of these experiments. 

of time and still remaineả firm were soaked for 24 hours in tap water and placed under favorable conitions for germination. The folloving taile shows the results of three tests of 25 firm seeds ench, after they had beon in a saturated solution of salt for 24 hours.

Table IV.

$\begin{array}{ccc}\text { Tests } & \text { G, } & I \\ 1 & 95 & 1.1 \\ 2 & 95 & 1.28 \\ 5 & 100 & 1.2\end{array}$

This table shors, as has already been stated, that germination taies place the same as though the seeds had never been soaked in Iracl solution. In the solutions of high concentration the number of seeds germinating depends entirely upon the number that fail to take up the solutions because of the impermeable nature of the seed coats. The coats of a complex sample of seeds vary widely as to the nature of the seed coats.

The experiments show very clearly that in solutions above a certain concentration the number of seeds capable of germination depends upon the number of firm seeds in the solution after soaking for 24 hours, i.e., the number whose merbranes are impermeable to the salt solution.

Plate number II shows this solution to be between ten per cent and eleven per cent, and after this corcentration is passed the number of seeds that will germinate corresponds very closely with the number of firm seeds in the solution after soalxing for 24 hours. 

The irregularieties in the curves, I believe, can be explained by the fact that the secd coats impermeable to salt solutions show a variable permeability to water. In placing such seeds on plaster blocks for germination, those only whose coats are readily permeable to water, swell and germinate.

Tho gramhs on plate rumber 3 represents the results as tabulated in table number $V$. This shows that the seed coats less permeable to liacl solutions will admit sufficient vater for germination when immersed in it for 24 hours.

The following table shows the number of firm seeds per hundred and the germination. These were talien from solutions of common salt varying from 1 ro to $35 \%$.

TIBIE V.

$\begin{array}{ccccccc}\% & \text { H. Seeds. } & G \% & \% & \text { H. Seeds. } & \text { G\% } \\ 1 & 6 & 6 & 19 & 10 & 4 \\ 2 & 6 & 6 & 20 & 7 & 5 \\ 3 & 1 & 1 & 21 & 9 & 7 \\ 4 & 4 & 3 & 22 & 8 & 7 \\ 5 & 6 & 5 & 23 & 9 & 7 \\ 6 & 10 & 10 & 24 & 8 & 8 \\ 7 & 9 & 8 & 25 & 12 & 10 \\ 8 & 11 & 11 & 26 & 10 & 10 \\ 9 & 10 & 9 & 27 & 15 & 11 \\ 10 & 9 & 7 & 28 & 15 & 12 \\ 11 & 7 & 7 & 29 & 14 & 12 \\ 12 & 9 & 8 & 30 & 14 & 10 \\ 13 & 7 & 7 & 31 & 14 & 13\end{array}$





$\begin{array}{rrrrrrr}9 & \text { H. S. } & \text { Gij } & \text { \% } & \text { H. S. } & \text { G\% } \\ 14 & 6 & 5 & 32 & 27 & 23 \\ 15 & 12 & 11 & 33 & 22 & 20 \\ 16 & 4 & 3 & 34 & 22 & 22 \\ 17 & 8 & 6 & 35 & 45 & 44 \\ 18 & 9 & 7 & & & \end{array}$

2000 Canada rinld reas soaked in distilled vater for 24 hours showed that lif are impermeable to water.

224 seeds that failed to swell in salt solutions of from 21. to $35 \%$ were taken from the solutions and soaked in distilled water for $24,48,72$, and 96 hours with the folloring results: Table VI.

Time in hours seeds swollen Total seeds Total renaining 24 148

48 26

72 19

96 16 209

of this number the coats of 15 were impermeable to water even after 96 hours. The above number (234) were all of the firm seeds obtained from 1500 peas soaked in salt solutions of from 21 to $35 \%$. The number (15) remaining firm after being soaled in water 96 hours is the same percent $(10)$ as found in the preceeding exreriment.

(b) Second series.- Tew Canada Field Peas rere obtained together with White liarrow-fat and Telephone peas.

The germination tests rere about the same for the fresher reas as they were for those of the first used. However soaking 

these peas in distilled rater 24 hours I failed to obtain any hard seeds as in the first Canada Field peas previously used. The following table shows the results obtained by soaking seeds for 24 hours in salt solutions.

\section{TABIE VII.}

$\begin{array}{cccccccc}\% & G \% & I & \text { S.G. } & \text { G } & \text { G\% } & I & \text { S. G. } \\ I & 90.8 & 1.6 & 1.0062 & 16 & 0 & C & 1.103 \\ 2 & 8 C .8 & 2.2 & 1.0125 & 17 & 2.2 & 2 & 1.110 \\ 3 & 67.7 & 2.2 & 1.0755 & 18 & 2.2 & 3.3 & 1.1175 \\ 4 & 30.5 & 2.2 & 1.0225 & 25 & 3.3 & 2.3 & 1.154 \\ 5 & 15.5 & 2.1 & 1.0287 & 26 & 3.3 & 4.0 & 1.1615 \\ 6 & 9.9 & 2.2 & 1.0362 & 27 & 4.3 & 3.6 & 1.170 \\ 7 & 0 & 0 & 1.0425 & 28 & 6.0 & 4.0 & 1.175 \\ 8 & 0 & 0 & 1.0485 & 29 & 8.0 & 4.0 & 1.179 \\ 9 & 0 & 0 & 1.0537 & 30 & 16.0 & 3.1 & 1.183 \\ 10 & 0 & 0 & 1.058 & 31 & 28.0 & 3.6 & 1.191 \\ 11 & 0 & 0 & 1.062 & 32 & 32.0 & 3.1 & 1.198 \\ 12 & 0 & 0 & 1.069 & 33 & 37.7 & 3.6 & 1.198 \\ 13 & 0 & 0 & 1.077 & 34 & 36.5 & 3.1 & 1.198 \\ 14 & 0 & 0 & 1.091 & 35 & 41.5 & 3.2 & 1.198 \\ 15 & 1 & 1 & 1.098 & & & & \end{array}$

It is seen from this table that all of the solutions are more or less injurious. From the 5\% solution all of the swelled seeds are killed. In $15 ;$ solutions re obtair one per cent germination; in 17, two per cent and in 18 five per cent. 411 of the seeds swelled up to fifteen per cent solution. In higher concentrations about $1 \%$ of the seeds soaked in salt solutions 

falled :0 swoll. This remained about the same at 16\% and $17 \%$ solution, but arose to $5 \%$ in the 18 per cont solution.

If the seeds are soaked for 24 hours in tap mater after soaking in salt solutions the time for germination is much reducod and tile number of seeds to germinate is much higher. This is clear from the table that follows:

\section{Table VIII.}

$\begin{array}{cccccccc}i & G, 0 & I & \text { S. G. } & \% & G, 0 & I & \text { S. G. } \\ 1 & 93.9 & 1.2 & 1.006 & 15 & 1.0 & 1.0 & 1.098 \\ 2 & 91.7 & 1.4 & 1.012 & 16 & 0 & 0 & 1.103 \\ 3 & 65.0 & 1.5 & 1.017 & 17 & 2 & 1 & 1.110 \\ 4 & 46.4 & 1.8 & 1.022 & 18 & 5 & 1 & 1.117 \\ 5 & 10.0 & 1.9 & 1.028 & 25 & 12.3 & 1.5 & 1.154 \\ 6 & 0.0 & 2.0 & 1.036 & 26 & 16.4 & 1.1 & 1.161 \\ 7 & 0.0 & 0 & 1.042 & 27 & 18.5 & 1.1 & 1.170 \\ 8 & 0.0 & 0 & 1.048 & 28 & 28.8 & 1.1 & 1.175 \\ 9 & 0.0 & 0 & 1.053 & 29 & 26.8 & 1.1 & 1.178 \\ 10 & 0.0 & 0 & 1.061 & 30 & 27.8 & 1.65 & 1.193 \\ 11 & 0.0 & 0 & 1.069 & 31 & 35.0 & 1.7 & 1.195 \\ 12 & 0.0 & 0 & 1.077 & 32 & 37.2 & 1.49 & 1.198 \\ 13 & 0.0 & 0 & 1.085 & 33 & 39.1 & 1.6 & 1.198 \\ 14 & 0.0 & 0 & 1.091 & 34 & 49.4 & 1.7 & 1.198\end{array}$

2.- Wite Warrov-fat peas.-

The following table gives the results of soaking white rarrow-fat reas in comon salt solutions for 24 hours and then placing them in a pan to germinate. 

TABIE IX.

$\begin{array}{cccccccc}S_{0} & G, 0 & I & \text { S.G. } & G_{0} & G \% & I & \text { S.G. } \\ 1 & 90.0 & 2.8 & 1.000 & 14 & 6.2 & 4.1 & 1.103 \\ 2 & 72.4 & 2.2 & 1.012 & 15 & 1.0 & 4.5 & 1.098 \\ 3 & 29.89 & 2.2 & 1.017 & 16 & 6.2 & 4.1 & 1.110 \\ 4 & 16.0 & 2.2 & 1.022 & 17 & 5.1 & 4.0 & 1.110 \\ 5 & 5.0 & 2.0 & 1.028 & 18 & 8.2 & 4.0 & 1.117 \\ 6 & 4.0 & 2.8 & 1.036 & 25 & 16.4 & 4.4 & 1.154 \\ 7 & 5.0 & 3.0 & 1.042 & 26 & 14.4 & 4.2 & 1.161 \\ 8 & 7.0 & 3.0 & 1.048 & 27 & 17.5 & 3.7 & 1.170 \\ 9 & 3.0 & 3.0 & 1.053 & 28 & 26.3 & 3.0 & 1.175 \\ 10 & 3.0 & 2.0 & 1.062 & 29 & 27.1 & 3.9 & 1.178 \\ 11 & 3.0 & 2.0 & 1.069 & 30 & 28.9 & 4.0 & 1.183 \\ 12 & 4.0 & 2.5 & 1.077 & 31 & 27.1 & 3.8 & 1.191 \\ 13 & 4.0 & 4.0 & 1.085 & 35 & 33.0 & 3.85 & 1.198\end{array}$

This table shovis some interesting results and in general agrees with the results obtained by Vandevelde. Plate Iumber 6 represents the curve of germination. There were some seeds in each solution that failed to swell after sonking for 24 hours in common salt solution. Leter passing the $4 \%$ solution the number of seeds germinating never exceeded the number of firm seeds taken from the solution. This shows that all seeds that swell in salt solutions above four per cent are killea.

When the White marrow-fatpeas vere soaked in tap vater for 24 hours after taken from the salt solutions, a much better and quicker germination resulted, as seer from the following tablo. 

IABIE X.

$\begin{array}{cccccccc}G & G \% & I & \text { S.G. } & \text { G } & G \% & I & S . G . \\ 1 & 95.8 & 1.8 & 1.006 & 14 & 5.2 & 1.4 & 1.085 \\ 2 & 75.0 & 1.7 & 1.012 & 15 & 3.1 & 2.0 & 1.098 \\ 3 & 37.5 & 1.7 & 1.022 & 16 & 5.2 & 1.0 & 1.103 \\ 4 & 18.7 & 1.6 & 1.028 & 17 & 5.2 & 1.4 & 1.111 \\ 5 & 6.25 & 1.5 & 1.032 & 18 & 8.3 & 2.0 & 1.1175 \\ 6 & 5.2 & 2.0 & 1.036 & 25 & 21.8 & 1.7 & 1.154 \\ 7 & 4.1 & 1.0 & 1.042 & 26 & 21.8 & 1.2 & 1.161 \\ 8 & 5.2 & 1.0 & 1.048 & 27 & 21.8 & 1.6 & 1.170 \\ 9 & 5.2 & 1.3 & 1.053 & 28 & 28.0 & 1.7 & 1.075 \\ 10 & 3.1 & 1.3 & 1.059 & 29 & 31.2 & 2.0 & 1.178 \\ 11 & 3.1 & 1.0 & 1.062 & 30 & 28.0 & 1.5 & 1.183 \\ 12 & 4.1 & 1.5 & 1.069 & 31 & 32.2 & 1.5 & 1.191 \\ 13 & 4.1 & 1.0 & 1.079 & & & & \end{array}$

This table is represented in the curve of plate number 7 . It shows the same general tendency of high germination in the low per cent solutions, a rapid falling off to five per cont then remaining noarly constant to 18 per cent.

Since large nurbers of seeds were required in order to mrke sure of correct results it was thought best to discoutinue this series of exporiments at $18, \%$ solution and go to $25 \%$ solution. The curvo shovs a considerave rise in germination from 18\%, to $25{ }^{\zeta}$.

The dotted line shows the probable rise in germination betwoon these two solutions. At any rate it is safe to say that tine rise in germination is rather rapid betweon these tro solu- 

tions and remains quite uniform until 31\% solution is reached. Here the experiments vere discontinued for this series.

\section{3.-Telephone Feas.}

Tolephone peas vere also tested for germination after beins soaled in sclt solutions of various concentrations as folloris:

\section{TABIE ZI.}

$\begin{array}{cccccccc}\% & G, 0 & I & \text { S.G. } & \text { G } & G, 0 & I & \text { S. G. } \\ 1 & 90.6 & 1.6 & 1.006 & 14 & 0.0 & 0.0 & 1.091 \\ 2 & 88.0 & 1.3 & 1.012 & 15 & 1.0 & 3.0 & 1.098 \\ 3 & 68.7 & 1.3 & 1.017 & 16 & 0.0 & 0.0 & 1.103 \\ 4 & 45.1 & 1.7 & 1.022 & 17 & 0.0 & 0.0 & 1.110 \\ 5 & 8.3 & 2.3 & 1.028 & 18 & 1.0 & 4.0 & 1.117 \\ 6 & 0.0 & 0.0 & 1.036 & 25 & 2.0 & 3.0 & 1.154 \\ 7 & 0.0 & 0.0 & 1.042 & 26 & 3.1 & 3.0 & 1.161 \\ 8 & 0.0 & 0.0 & 1.048 & 27 & 3.1 & 3.0 & 1.170 \\ 9 & 0.0 & 0.0 & 1.053 & 28 & 3.1 & 2.6 & 1.175 \\ 10 & 0.0 & 0.0 & 1.060 & 29 & 5.2 & 3.0 & 1.178 \\ 11 & 0.0 & 0.0 & 1.069 & 30 & 9.3 & 4.0 & 1.183 \\ 12 & 0.0 & 0.0 & 1.077 & 31 & 9.3 & 4.0 & 1.191 \\ 13 & 0.0 & 0.0 & 1.085 & 35 & 10.5 & 3.5 & 1.198\end{array}$

From this table it is evident that one and two per cent solutions have little effect on germination of the seeds, that germination decreases very rapidy, and from 6 to 15\% solutions all germs are killed. One per cent of the peas soaked in $15 \%$ solution germinated. In a $16 \%$ solution and a 17,0 solution no seeds germinated. The $n$ moer germinating after soaking in solutions of $\mathrm{NaCl}$ 

from 18 to 30, was practically constant. The curve representing this table is secn in plate 8 .

III.- Summary and Conclusion.

iie may thus agree with Vandevelde, that dilute solutions are easily absorbea; the more concentrated the solution, the smaller the power of diffusion. In a saturated solition somo of the seods do not swell and these are the ones that are found to germinate.

We find, also from the results here tabulated, that the permeavility of the seed coats varies some-what with the variety of poas used in the experiments, and after a certin per cent solution is passed all seeds that swell are killed. 



.Plato III. 18. 



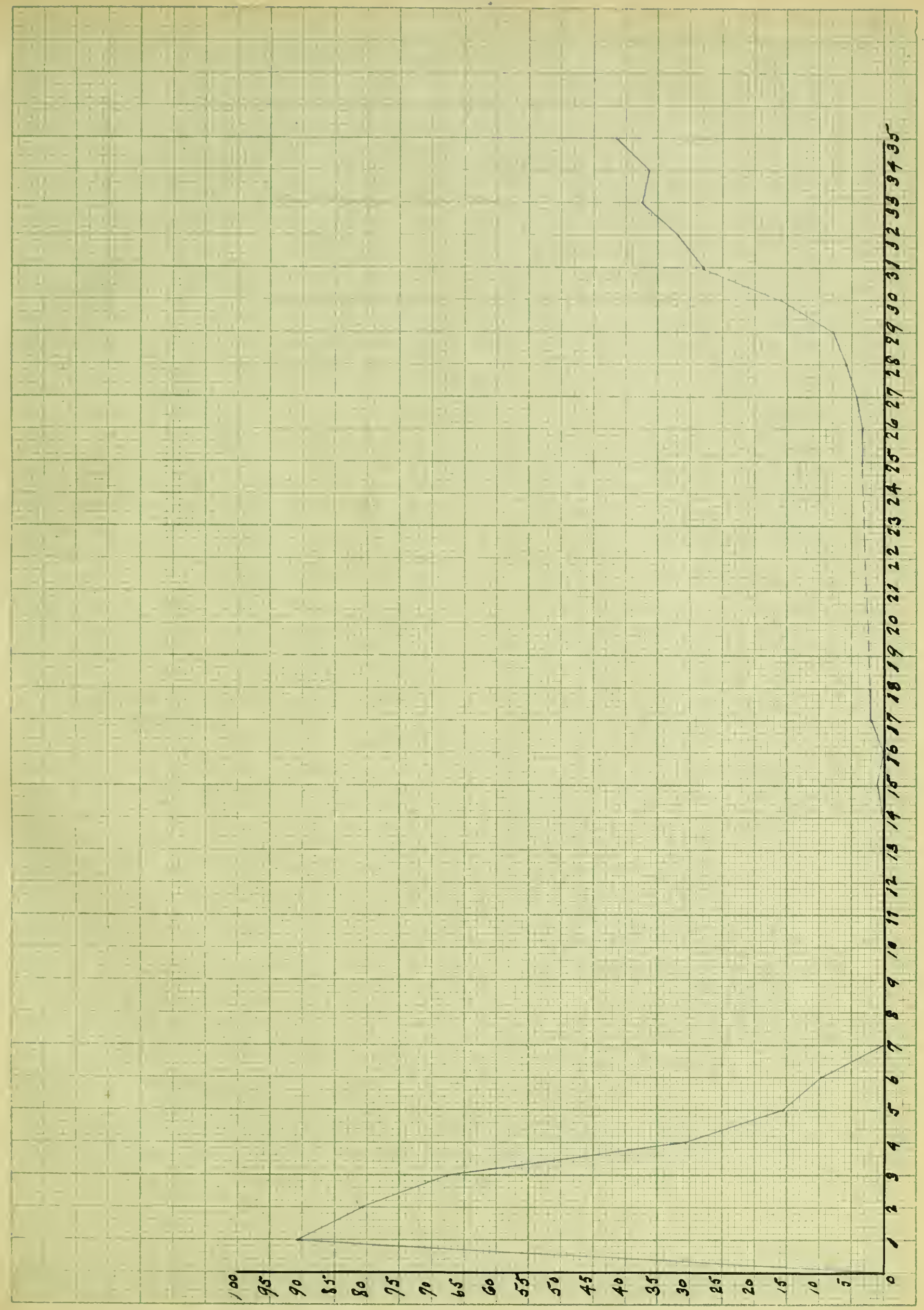

Canada field peas, 2ni. series, Gó curve. 


Ilate VI. 2$]$.

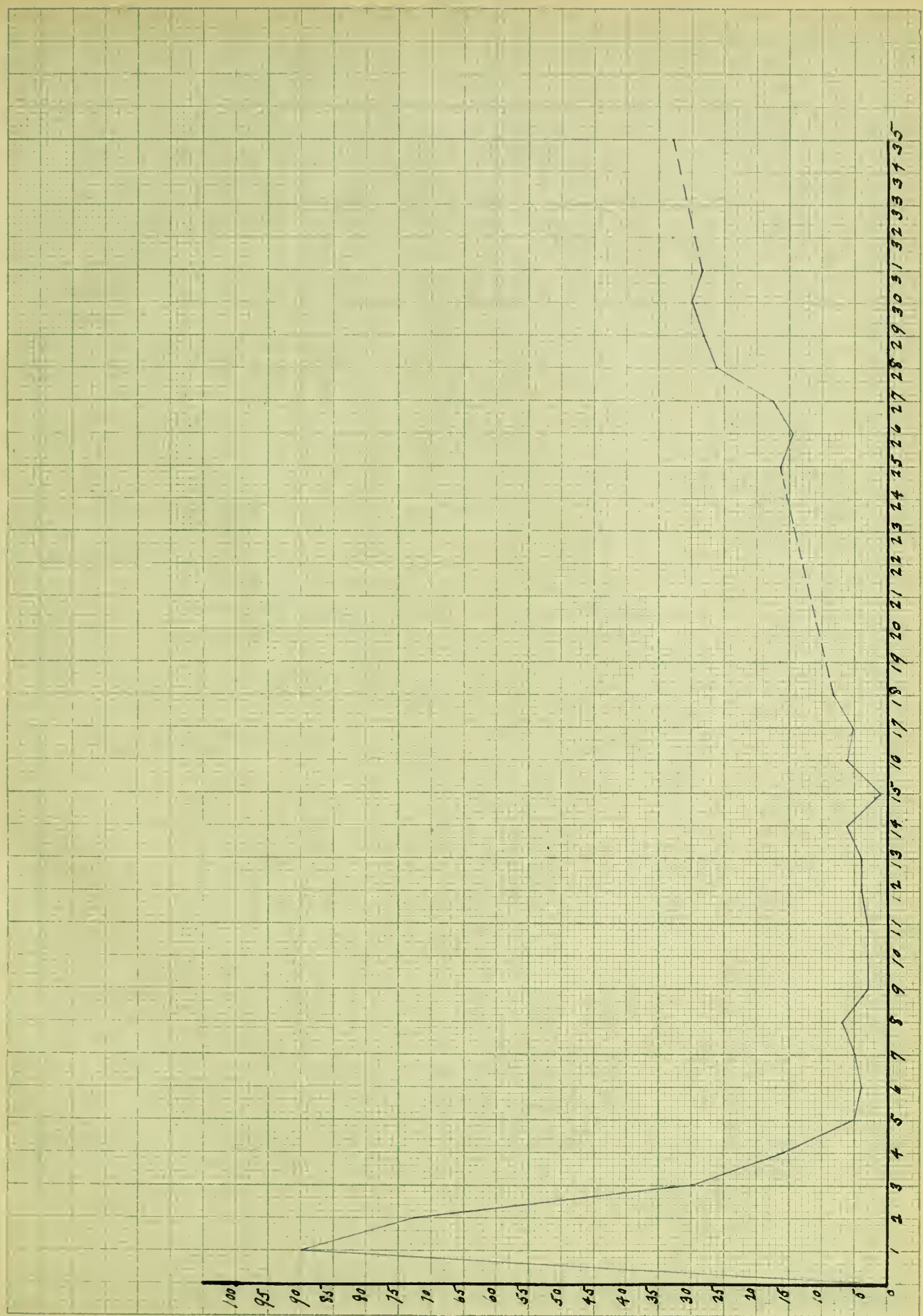

White Iarrow peas. $G c_{\mu}^{\prime}=$ ordinates. $c_{0}^{\prime}=a b c i s s a s$. 



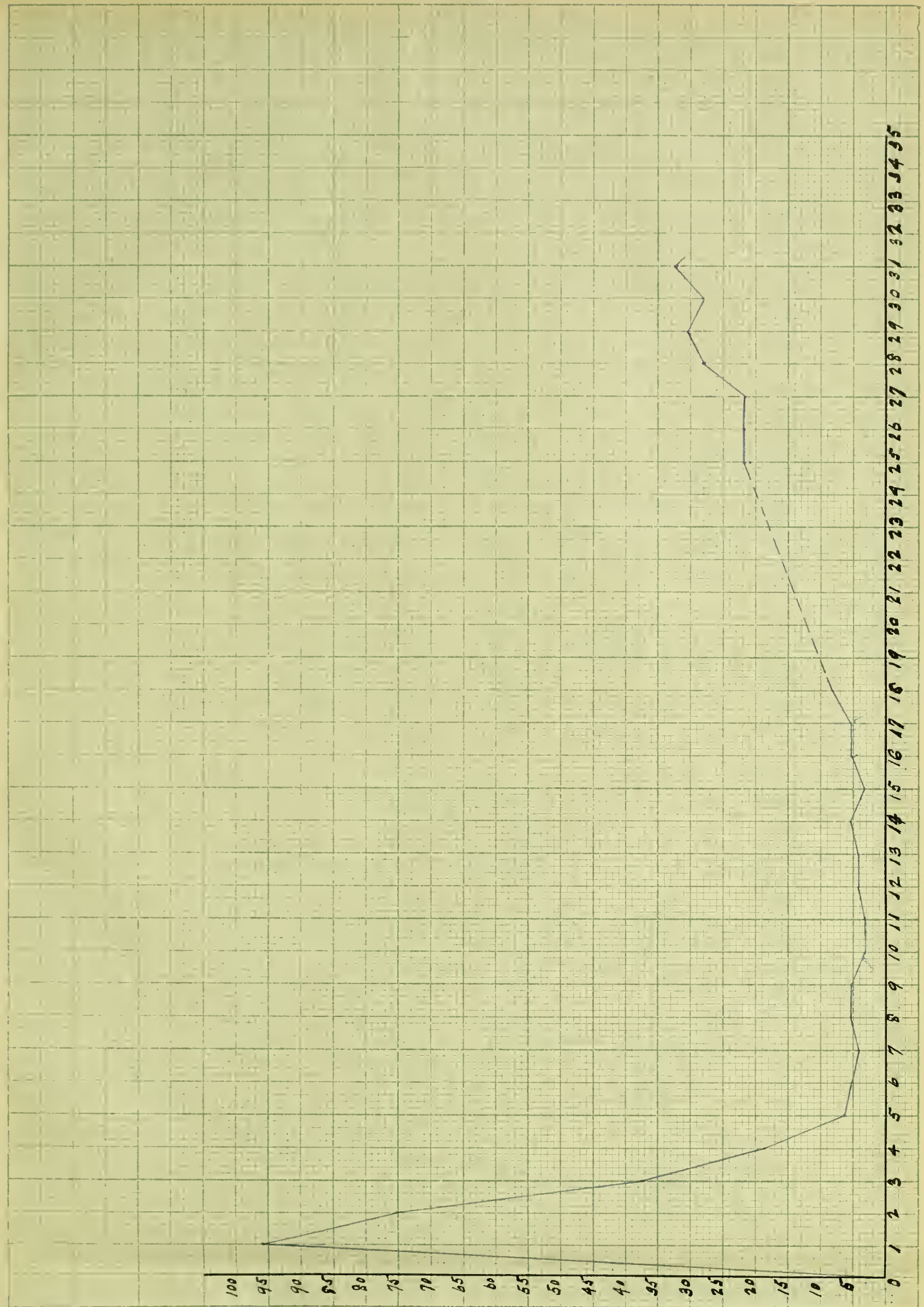

inite :arrom fat peas--soarea 24 hrs. in snlt solutions and $2 \leqslant$. hrs. in $\tan$ in $c . \quad G_{0}^{\prime}=$ orcinates. $\quad c_{1}^{\prime}=$ abcissas. 



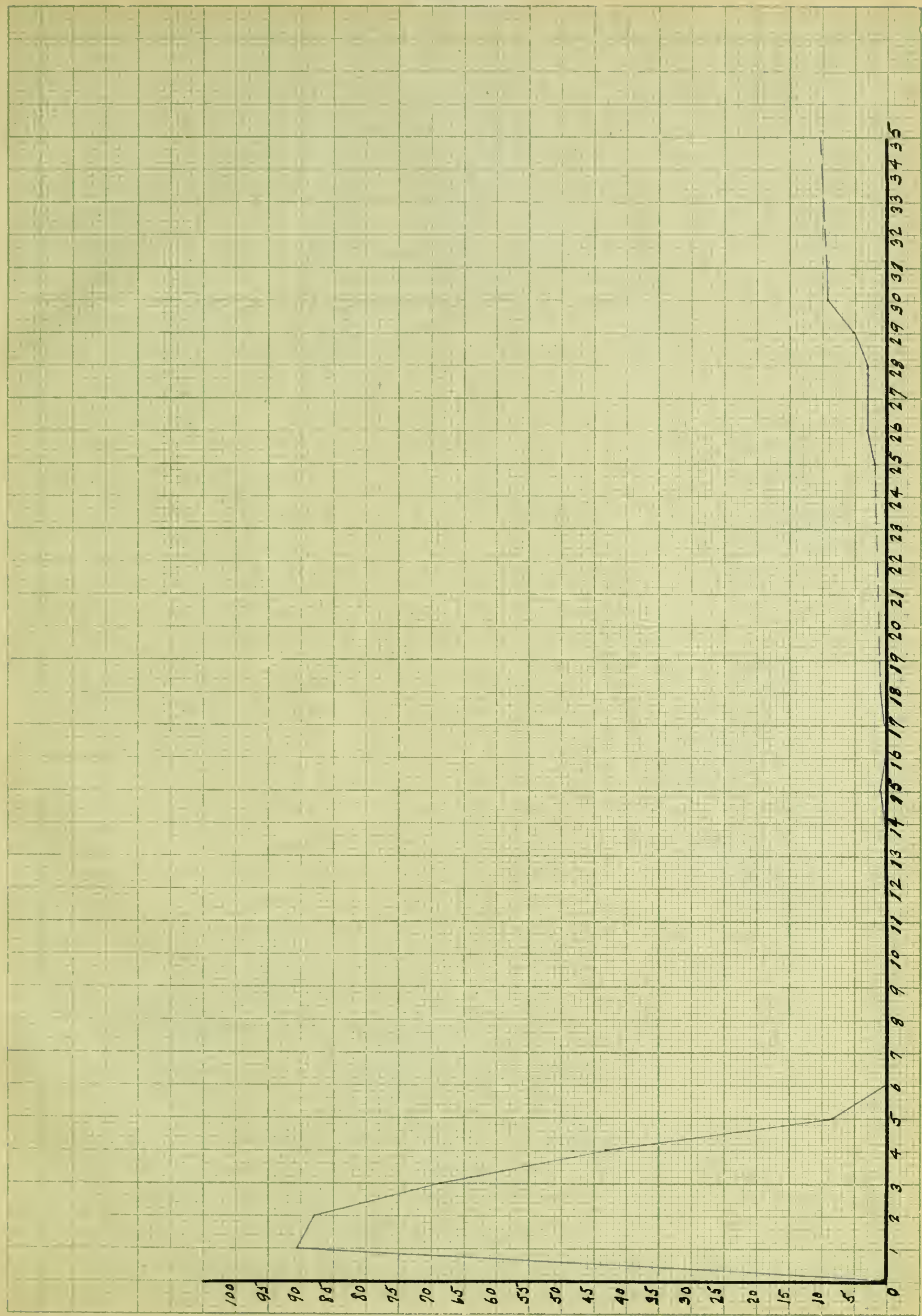

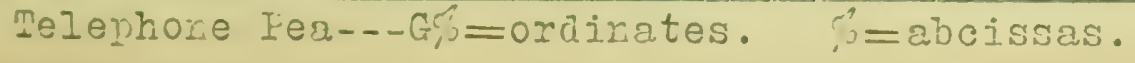




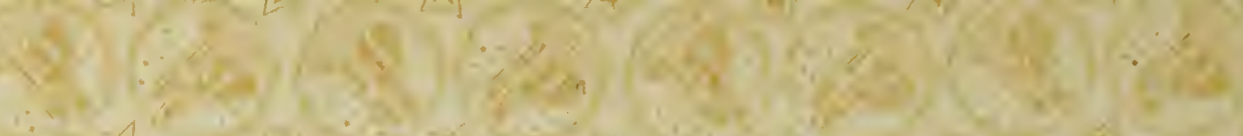

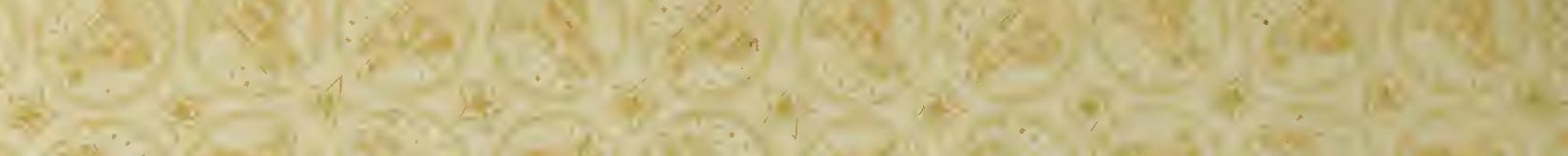

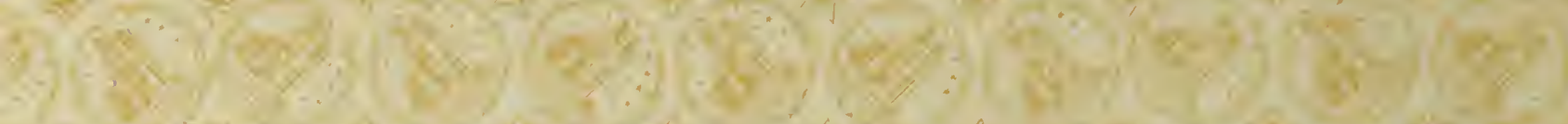

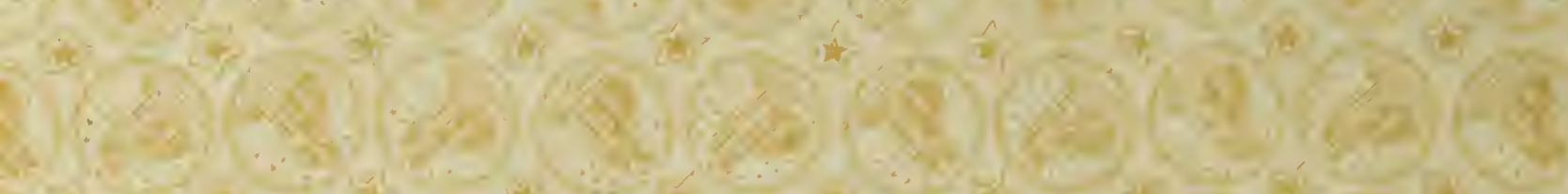

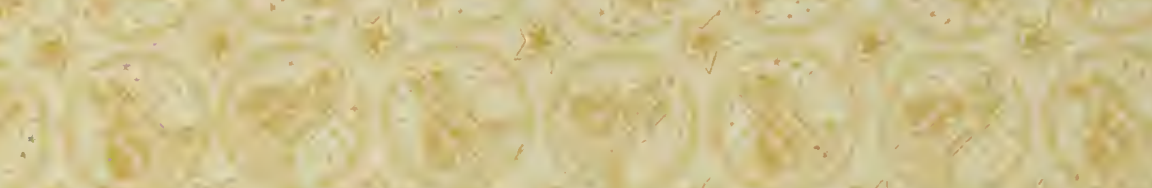 at 4. . त है?

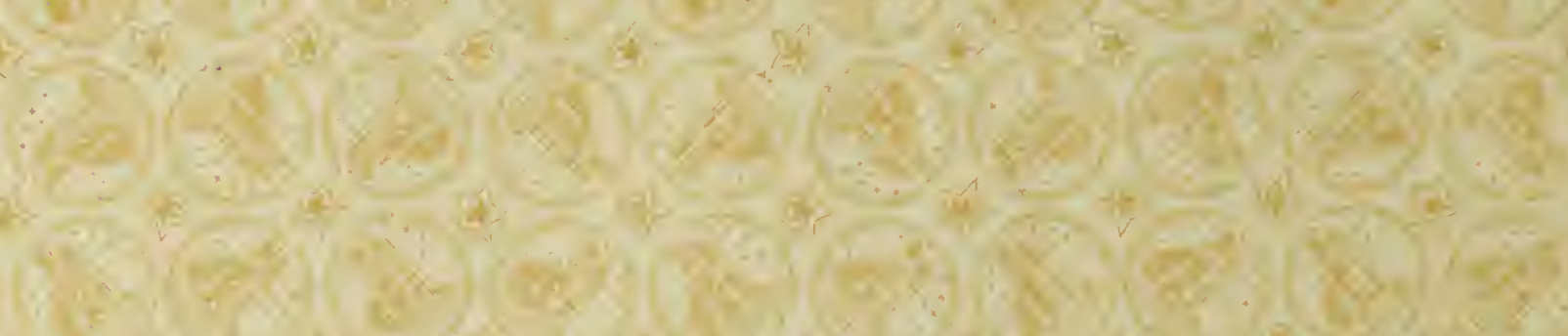
$(807)(82)$

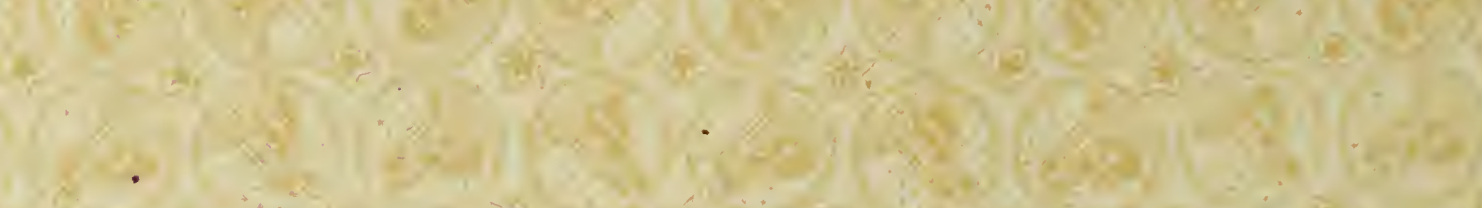

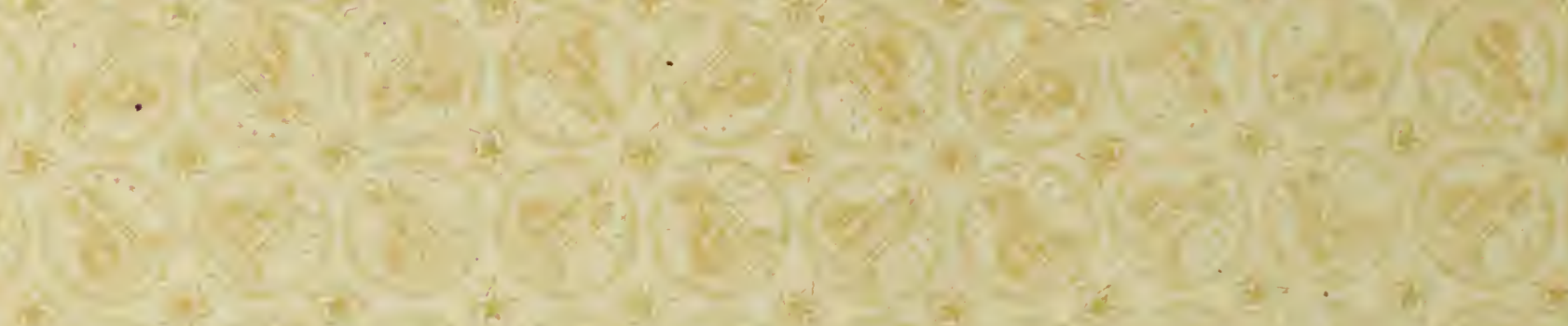
at ton

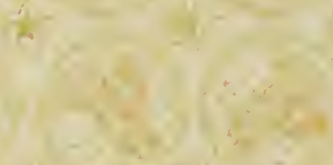

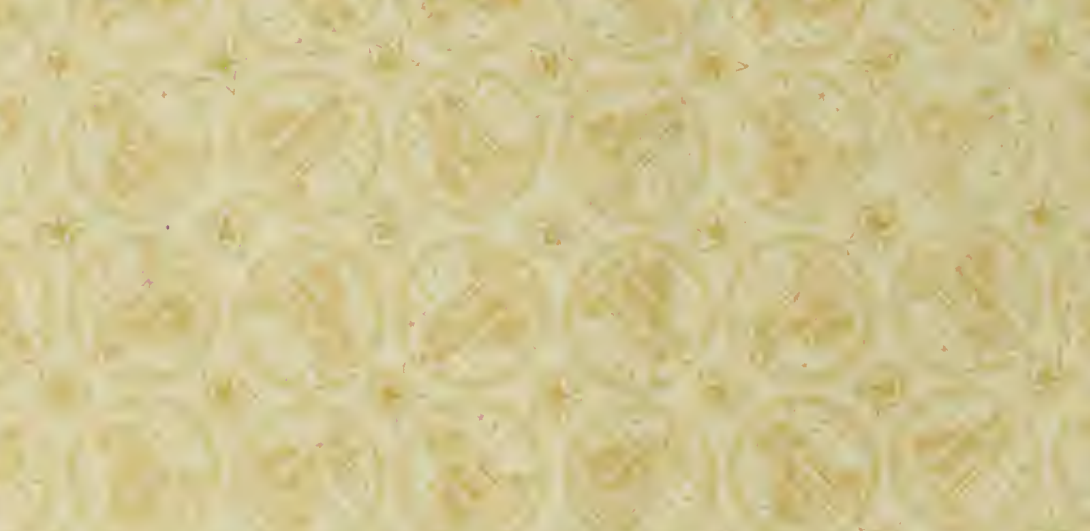

19.

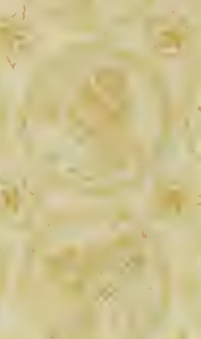

I)

-4)

$+2$
2.
(-1).

$1 x^{3}: \frac{1}{4}$

(4) 


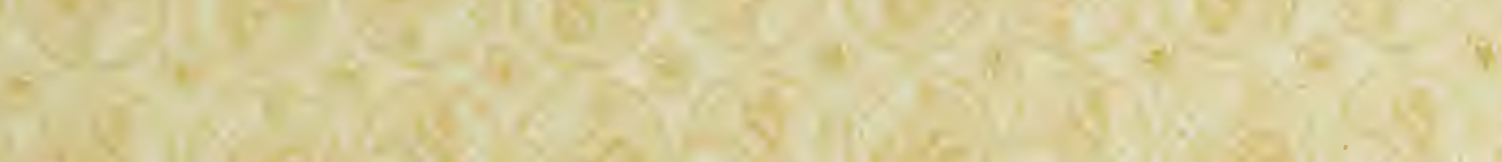

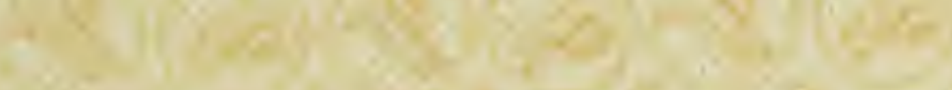

s. 173

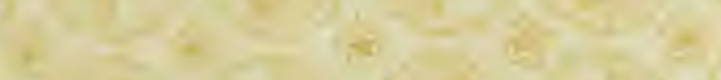

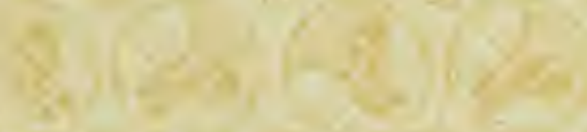
4.

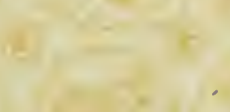
$x^{2}+2$

69

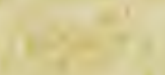

$+2$

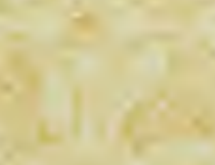

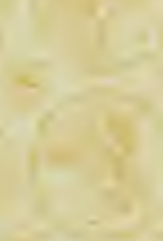

$+$

\section{$\infty$}




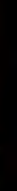

$\cos i^{3}+x^{\circ}$

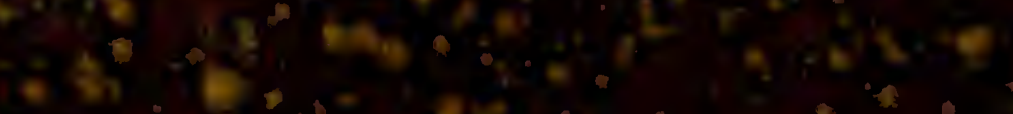

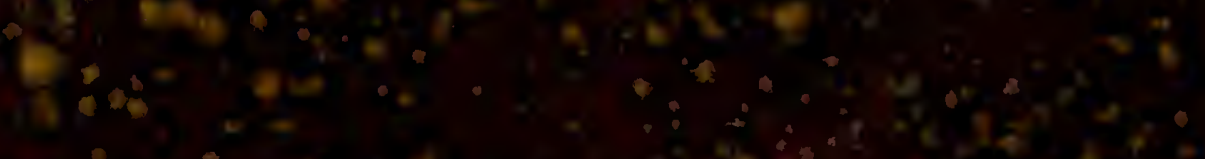

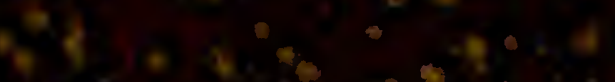
a.

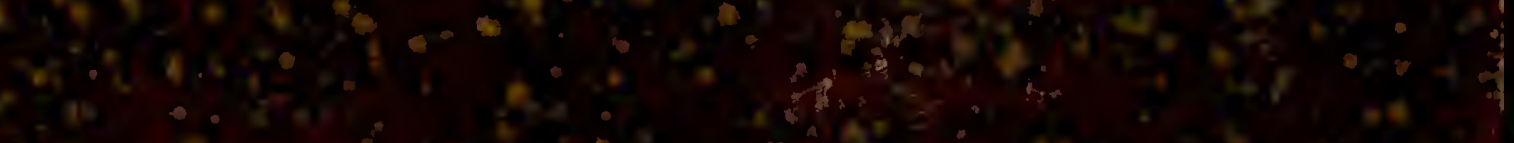

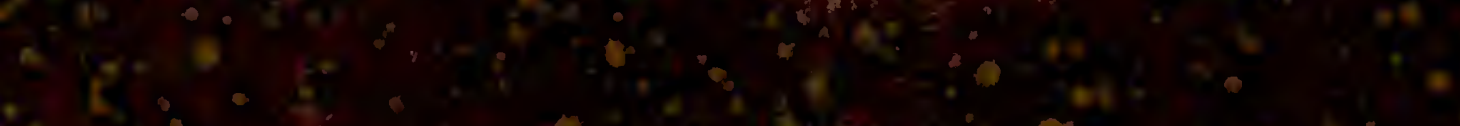

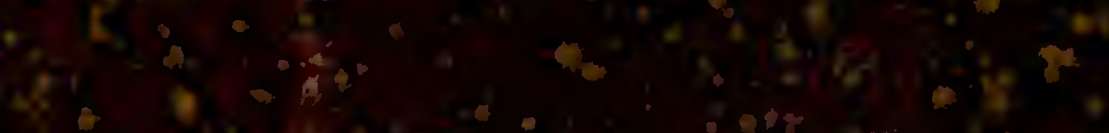

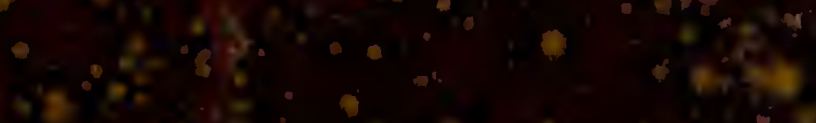

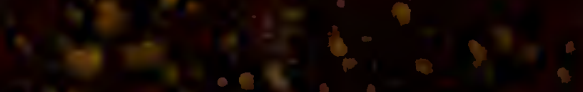

